\title{
Assessing pre-operative nutritional status in geriatric inpatients, and associating it with post-operative clinical outcomes'; in a tertiary care hospital of central India
}

\author{
Nidhi D. Sinha ${ }^{1}$, Krishna Valecha ${ }^{2}$, B.N. Mishra ${ }^{3, *}$, Vandana Sisodiya ${ }^{4}$, S.C. Mohapatra ${ }^{5}$ \\ ${ }^{1}$ Associate Professor, ${ }^{2}$ Intern, ${ }^{3}$ Professor, ${ }^{4}$ Tutor, ${ }^{5}$ Dean Academics \& Professor, ${ }^{1}$ Dept. of Dental, ${ }^{3-5}$ Dept. of Community Medicine, ${ }^{1-4} \mathrm{R}$. \\ D. Gardi Medical College, Ujjain, Madhya Pradesh, ${ }^{5}$ SGT University, Gurugram, Haryana, India \\ *Corresponding Author: B.N. Mishra \\ Email: badrinmishra@gmail.com
}

\begin{abstract}
Introduction: Malnutrition though prevalent during hospitalization is often unrecognized in geriatric population. The study aimed to determine the prevalence of malnutrition among hospitalized geriatric patients undergoing elective surgery using a standardized nutritional tool and to find association between the pre-operative nutritional status and post-operative clinical outcomes.

Materials and Methods: This observational follow up study was conducted at a tertiary care hospital of Central India. Total 90 patients were included. Each patient's nutritional status was determined by MNA (Mini Nutritional Assessment) scale within 24 hours of admission and required anthropometric and biochemical parameters were also collected preoperatively. Patients were followed with respect to surgical wound healing and length of hospital stay.

Results: MNA tool detected the prevalence of malnutrition (under-nutrition) at $60 \%$, and at risk of Malnourishment at $24 \%$. These patients experienced significantly prolonged hospital stay after surgery $(\mathrm{p}<0.01)$. The MNA based nutritional grading showed high level of sensitivity $(91 \%-94 \%)$ specificity $(92 \%-95 \%)$, predictive value $(91 \%-94 \%)$ and concordance coefficient $(70 \%-90 \%)$.

Conclusion: Large number of geriatric surgical patients are malnourished or at risk for malnutrition. MNA, a simple low skilled tool that can be conducted by paramedics can identify this with good accuracy and help in nutritional planning and lowering postoperative complications.
\end{abstract}

Keywords: Nutritional status. Surgical geriatric in patients, MNA.

\section{Introduction}

Aging is a constant, irreversible and an inescapable process involving changes from birth to senescence. The wave of greying in terms of number and proportion is seen all over the world. ${ }^{1}$ The geriatric population which is growing at a rate of about 3 percent per year presently constitutes 13 percent of the global population and this number is expected to double by $2050 .^{2}$ India's geriatric profile stands at 77 million (7.5\%) elderly in 2001 to 104 million (8.6\%) in 2011 and the number is forecasted to triple by $2050 .^{3-4}$ Their increasing number brings cheers and challenges that needs pragmatic approaches to ensure their health and wellbeing. One such area is geriatric undernutrition..$^{5-11}$ This issue gets further compounded when surgical procedures which themselves are nutritionally demanding situations are considered at an increased rate in this venerable populace. ${ }^{12-16}$ Timely address of this issue can be a cost and recovery effective approach.

\section{Aim and Objectives}

The present study was designed to evaluate preoperative nutritional status and its association with postoperative clinical outcomes in geriatric inpatients of a tertiary care hospital of Central India with the following objectives:

1. To estimate the prevalence of under nutrition / at risk of malnutrition in geriatric inpatients admitted to Surgery Wards.

2. To study post-operative clinical outcome in terms of surgical wound healing and length of hospital stay with reference to nutritional status.
3. To determine the feasibility of adopting MNA (Mini Nutritional Assessment) scale as an assessment tool to identify patients with malnutrition or at risk of malnutrition for geriatric in patients.

\section{Materials and Methods}

A prospective Observational study was carried out in Surgical Units of C. R. Gardi Hospital of R.D. Gardi Medical College, Ujjain, Madhya Pradesh from $15^{\text {th }}$ May 2018 to $15^{\text {th }}$ July 2018. Patients above 60 years of age undergoing elective surgery formed the study population.

Sample size was calculated by using the formula $n=z^{2} p$ $(1-\mathrm{p}) / \mathrm{d}^{2}$, where $\mathrm{n}$ is the sample size, $\mathrm{z}$ the confidence coefficient, $\mathrm{p}$ is the prevalence and $\mathrm{d}$ is the allowable error. Considering the value of $\mathrm{z}$ at $95 \%$, confidence level to be 1.96, and prevalence of malnutrition and at risk of nutritional among geriatric inpatients to be $60 \%{ }^{31}$ and maximum allowable error at $10 \%$ the calculation yielded a required sample of 92 that was rounded off to 90 .

Selection Criteria: Consenting patients above 60 years of age admitted for elective surgery who were able to understand and answer the question were assessed for their nutritional status within 24 hours of admission by MNA, relevant anthropometric, and biochemical markers. Patients with terminal illness like cancers, confided to bed, on steroid therapy and with a habit of smoking and alcohol and unable to communicate were kept out.

The outcome variables like wound infections and length of hospital stay was also recorded from the patient's bed side files and discharge records.

The study had permission from Institutional Ethics Committee- of R.D. Gardi Medical College. 


\section{Results}

General socio-demographic profile was recorded and nutritional assessment done by MNA (sensitivity $96 \%$, and specificity 98\%) which has four domains i.e. dietary, subjective, psychological and anthropometric measurements. Nutritional biomarkers like haemoglobin and serum albumin values were collected from the bedside admission files and anthropometric measurements like height, weight, and mid-upper arm and calf circumferences were recorded by the investigator by standardized equipments established guidelines. Literature supported MNA as a preferred tool especially for geriatric surgical population. ${ }^{17}$ It has a screening and assessment part. Those who scored less than 17 were classified as undernourished, who scored between 17 and 23.5 as at risk of malnutrition and who scored 24 to 30 were classified to have normal nutritional status. The Biuret and BCG methods were employed in the assessment of Serum albumin. Haemoglobin estimation was done by Cyanmetheamoglobin method. Subjects having s. albumin below $3.5 \mathrm{gm} / \mathrm{dL}$ and haemoglobin levels below $12 \mathrm{gm} / \mathrm{dL}$ were considered as undernourished. ${ }^{32,33}$

Different outcome measures like would status was recorded at $3^{\text {rd }}$ postoperative day. Impaired wound healing was defined as presence of any evidence of wound infection such as expanding redness, pus discharge, increased swelling, tenderness, or pain around the wound. Wound status was recorded regularly till the discharge of the patient. $^{34}$

Length of hospital stay (LOHS), the most important proxy indicator of recovery was recorded. ${ }^{35}$ The standard policy at the hospital is to discharge patients within 7 days of routine surgery providing there are no complications.

\section{Data Analysis}

All data were entered into a Microsoft Excel (Microsoft Corporation, Redmond, WA, USA) spreadsheet and statistically analysed using SPSS version 23.0 (SPSS Inc., Troy, NY, USA). Descriptive data were presented in frequencies and percentages or means and standard deviations. Inferential analysis was done for study of association between nutritional status as per MNA and outcome variables. Utility of MNA as an assessment tool was reported via sensitivity, specificity, positive predictive value (PPV), negative predictive value (NPV) and concordance.

\section{Descriptive Analysis}

The age, gender, education and livening status of studied participants are presented in table 1.

Majority patients underwent abdominal 32 (37\%) and gynaecological $30(33.3 \%)$ surgery. Urogenital and other surgeries were performed on 11(12\%) and 17(19\%) participants respectively.

Nutritional status evaluation by MNA showed that 54 $(60 \%)$ of the subjects as malnourished (having MNA score of less than 17), 22(24\%) at risk of malnutrition (MNA score between 17 and 23.5) and 14 (15.6\%) were having adequate nutritional status (MNA score above 23.5). This is depicted in figure number 2 by pie-chart.

Post-operative clinical outcome was assessed in terms of wound healing and LOHS. Wound infection was present in 14 patients $(15.6 \%)$ and $42(46.7 \%)$ patients reported longer LOHS. These data are shown in table 2.

Table 1: Demographic characteristics of the study participants

\begin{tabular}{|c|c|c|c|}
\hline Variables & & $\mathrm{N}=90$ & Percentage \\
\hline \multirow{3}{*}{$\begin{array}{l}\text { Age } \\
\text { (years) }\end{array}$} & $<70$ & 52 & $57.7 \%$ \\
\hline & $70-80$ & 28 & $31.1 \%$ \\
\hline & $>80$ & 10 & $11.11 \%$ \\
\hline \multirow[t]{2}{*}{ Gender } & Male & 47 & $52 \%$ \\
\hline & Female & 43 & $48 \%$ \\
\hline \multirow[t]{2}{*}{ Residence } & Rural & 85 & $94 \%$ \\
\hline & Urban & 5 & $6 \%$ \\
\hline \multirow[t]{2}{*}{ Education } & $\begin{array}{c}\text { Unable to read and } \\
\text { write }\end{array}$ & 80 & $87 \%$ \\
\hline & $\begin{array}{l}\text { Able to read and } \\
\text { write }\end{array}$ & 10 & $11 \%$ \\
\hline \multirow{2}{*}{$\begin{array}{l}\text { Living } \\
\text { Status }\end{array}$} & Living alone & 39 & $43 \%$ \\
\hline & $\begin{array}{l}\text { Living with } \\
\text { family/others } \\
\text { Others }\end{array}$ & 51 & $57 \%$ \\
\hline
\end{tabular}

\section{Inferential Analysis}

On demographic parameters increasing age was found significantly associated with mal-nutrition $(p<0.05)$. Other parameters reported statistical non-significance. The chi square analysis is shown in table 3 .

Table 2: Descriptive analysis of post-operative clinical outcomes

\begin{tabular}{|l|c|c|c|}
\hline Variables & & N=90 & Percentage \\
\hline Surgical wound status & Normal healing & 76 & $84.4 \%$ \\
\cline { 2 - 4 } & Delayed healing & 14 & $15.6 \%$ \\
\hline \multirow{2}{*}{ Length of stay } & Normal & 48 & $53.3 \%$ \\
\cline { 2 - 4 } & Increased & 42 & $46.7 \%$ \\
\hline
\end{tabular}


Table 3: Study of association of nutritional status with demographic variables

\begin{tabular}{|c|c|c|c|c|}
\hline Variable & Malnourished & Risk of malnutrition & Well Nourished & p-value \\
\hline \multicolumn{5}{|l|}{ Age } \\
\hline$<=70$ years $(n=52)$ & $32(61.53 \%)$ & $11(21.15 \%)$ & $9(1 \%)$ & \multirow{3}{*}{0.04} \\
\hline $70-80$ years $(n=28)$ & $14(50.00 \%)$ & $9(32.14 \%)$ & $5(17.85 \%)$ & \\
\hline$>80$ years $(n=10)$ & $8(80.00 \%)$ & $2(20.00 \%)$ & $0(0.00 \%)$ & \\
\hline \multicolumn{4}{|l|}{ Sex } & \multirow{4}{*}{0.71} \\
\hline Females $(n=43)$ & $30(69.76 \%)$ & $10(23.25 \%)$ & $3(6.98 \%)$ & \\
\hline Males $(n=47)$ & $24(51.06 \%)$ & $12(25.53 \%)$ & $11(23.40 \%)$ & \\
\hline \multicolumn{4}{|l|}{ Education } & \\
\hline Illiterate $(\mathrm{n}=80)$ & $46(57.5 \%)$ & $20(25 \%)$ & $14(77.77 \%)$ & \\
\hline Literate $(n=10)$ & $8(80.0 \%)$ & $2(20.0 \%)$ & $0(0.0 \%)$ & \multirow[t]{2}{*}{0.27} \\
\hline \multicolumn{4}{|l|}{ Address } & \\
\hline Rural $(n=85)$ & $52(61.17 \%)$ & $21(24.7 \%)$ & $12(14.1 \%)$ & \multirow[t]{2}{*}{0.29} \\
\hline Urban $(n=5)$ & $2(40.0 \%)$ & $1(20.0 \%)$ & $2(40.0 \%)$ & \\
\hline \multicolumn{4}{|l|}{ Living Status } & \multirow{3}{*}{0.48} \\
\hline Living alone $(n=38)$ & $25(65.78 \%)$ & $9(23.68 \%)$ & $4(10.52 \%)$ & \\
\hline $\begin{array}{l}\text { Living with others } \\
(\mathrm{n}=52)\end{array}$ & $29(55.76 \%)$ & $13(25 \%)$ & $10(19.23 \%)$ & \\
\hline
\end{tabular}

(Chi square analysis, $\mathrm{p}$-value significant at $<0.05$ )

Nutritional score/category of MNA was evaluated against anthropometric and biochemical variables. BMI (body mass index), haemoglobin and serum albumin levels demonstrated strong association with MNA nutritional grades $(\mathrm{p}<0.01)$. The chi square analysis is presented in table 4.

Post-operative clinical outcome was studied in terms of surgical wound healing and length of stay. Increased hospital stay was highly associated with patient's nutritional status (p, 0.00). This data is shown in Table 5.

MNA showed a sensitivity of $67 \%$ with BMI, $70 \%$ with MAC and $72 \%$ with $\mathrm{CC}$. When biochemical parameters were taken as gold standard, MNA showed a sensitivity of $95 \%$ with S. albumin and $89 \%$ with haemoglobin. On using MAC, specificity of MNA was average $(48 \%)$ but it was high $(92 \%)$ when S. albumin and haemoglobin were used. Predictive values of MNA i.e. probability to accurately identify truly malnourished was quite high $91 \%$ and $94 \%$ with biochemical indices. On concordance coefficient analysis, MNA had $70 \%$ inter-observer reliability with $\mathrm{S}$. albumin and $90 \%$ with haemoglobin. Details are presented in in Fig. 1.

Table 4: Study of association of anthropometric and biochemical measurements with nutritional status as per MNA

\begin{tabular}{|c|c|c|c|c|}
\hline Study Variable & $\begin{array}{c}\text { Malnourish } \\
\text { ed }\end{array}$ & $\begin{array}{c}\text { Risk of } \\
\text { malnutrition }\end{array}$ & $\begin{array}{c}\text { Well } \\
\text { Nourished }\end{array}$ & p-value \\
\hline \multicolumn{5}{|l|}{ BMI $\left(\mathrm{kg} / \mathrm{m}^{2}\right)$} \\
\hline$<19(\mathrm{n}=21)$ & $21(0.0 \%)$ & $0(0.0 \%)$ & $0(0.0 \%)$ & \multirow[t]{4}{*}{0.01} \\
\hline $19-21(n=57)$ & $30(65.4 \%)$ & $15(19.2 \%)$ & $12(15.4 \%)$ & \\
\hline $21-23(n=11)$ & $2(18.2 \%)$ & $7(63.6 \%)$ & $2(18.2 \%)$ & \\
\hline$>23(n=1)$ & $1(100.0 \%)$ & $0(0.0 \%)$ & $0(0.0 \%)$ & \\
\hline \multicolumn{5}{|l|}{ MAC (in cm) } \\
\hline$<21(n=45)$ & $26(57.8 \%)$ & $11(24.4 \%)$ & $8(17.8 \%)$ & \multirow[t]{3}{*}{0.07} \\
\hline $21-22(n=30)$ & $23(76.7 \%)$ & $4(13.3 \%)$ & $3(10.0 \%)$ & \\
\hline$>22(n=15)$ & $5(33.3 \%)$ & $7(47.7 \%)$ & $3(20.0 \%)$ & \\
\hline \multicolumn{5}{|l|}{$\mathrm{CC}$ (in cm) } \\
\hline$<31(n=82)$ & $49(59.8 \%)$ & $20(24.4 \%)$ & $13(15.9 \%)$ & \multirow[t]{2}{*}{0.96} \\
\hline$>31(n=8)$ & $5(62.5 \%)$ & $2(25.0 \%)$ & $1(12.5 \%)$ & \\
\hline \multicolumn{5}{|l|}{ S. Albumin (gm/dl) } \\
\hline Low $(n=33)$ & $30(90.9 \%)$ & $3(9.1 \%)$ & $0(0.0 \%)$ & \multirow[t]{2}{*}{0.00} \\
\hline Normal $(n=57)$ & $24(42.1 \%)$ & $19(33.3 \%)$ & $14(24.6 \%)$ & \\
\hline \multicolumn{5}{|l|}{ Haemoglobin (gm/dl) } \\
\hline Low $(n=51)$ & $48(94.1 \%)$ & $3(5.9 \%)$ & $0(0.0 \%)$ & \multirow[t]{2}{*}{0.00} \\
\hline Normal $(n=39)$ & $6(15.4 \%)$ & $19(48.7 \%)$ & $14(35.9 \%)$ & \\
\hline
\end{tabular}

(Chi square analysis, $\mathrm{p}$-value significant at $<0.05$.) 


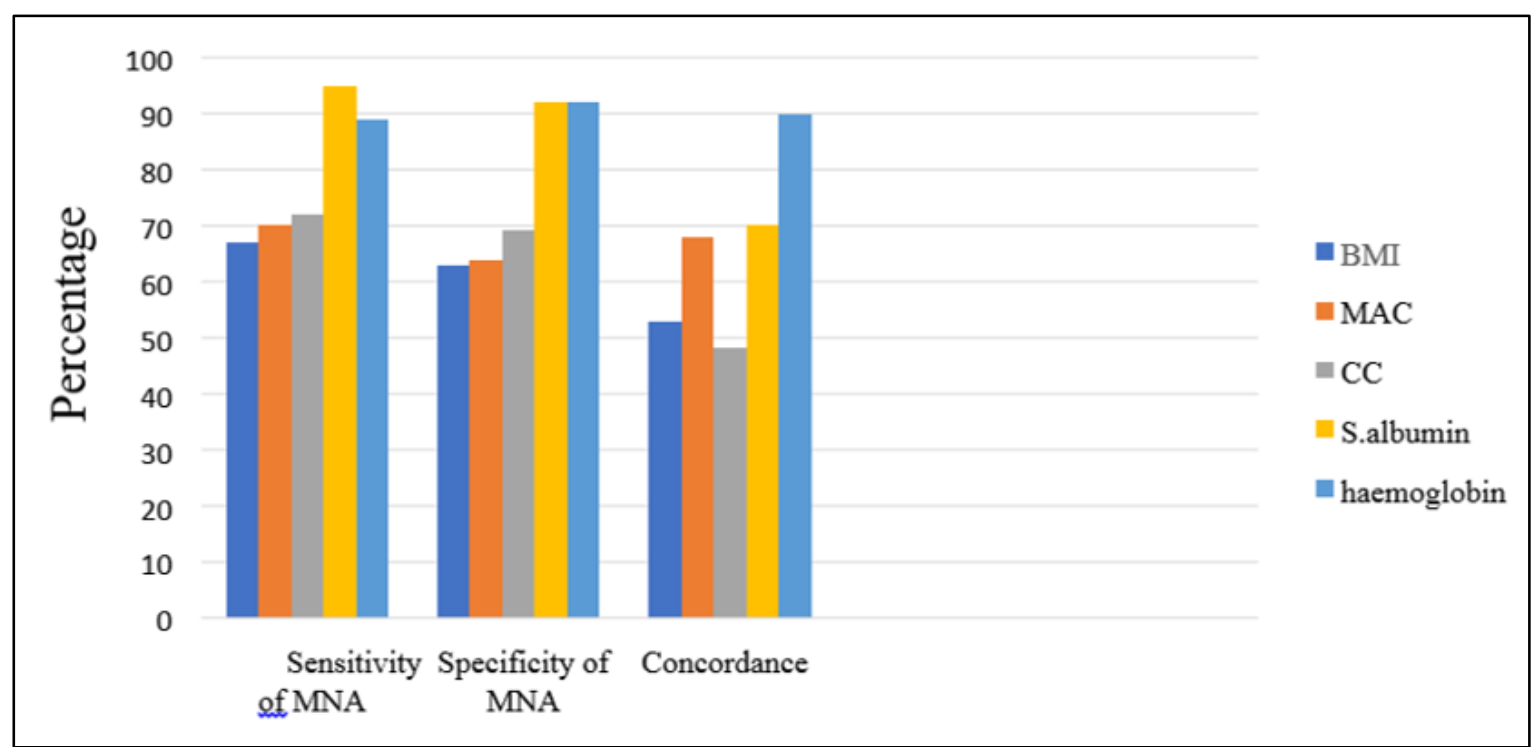

Fig. 1: Graph showing sensitivity, specificity and concordance of MNA

\section{Discussion}

Malnutrition is a concerning issue in geriatrics more so those seeking operative interventions as surgical conditions and surgical procedures in themselves are major stress factors thereby emphasising on good nutritional status which allows the body to recover in a faster and more efficient manner. ${ }^{36}$

The reported study focuses on the prevalence of malnutrition among geriatric surgical patients, its association with post-operative clinical outcomes and validation of MNA as a locally contextual tool in this regard.

It was observed that $60 \%$ of the geriatric patients were malnourished and 24\% were at risk of it. Study done by Vivek Nagar et al, showed the general prevalence of malnutrition among the patients at $36 \%$ and those at risk at $38 \% .{ }^{37}$ Chandrashekhar $\mathrm{C}$. et al found the prevalence in surgical patients to be $49 \%$ and at risk of malnutrition at $45 \% .^{38}$ Both these studies did not have geriatric population in focus. The reason for higher figure in present study may be attributed to the hospitalized geriatric patients seeking surgery.

The study pointed out at age as an independent risk factor for malnutrition in surgical geriatric inpatients $(p$ value $=0.04)$. This result was congruent to the other studies where age was also found as an independent risk factor for malnutrition. ${ }^{31,39}$ Higher prevalence was also observed in females (46\%) compared to males (7\%) though this difference could not achieve statistical significance. Literature review shows studies reporting significantly higher mal (under) nutrition in females than males using MNA tool. ${ }^{40,41}$ Rural vs. urban and educated vs. illiterate line could not be toed.

In establishing MNA as an efficient screening tool the anthropometric scale of BMI showed significant accusation and MAC a near significant (p-0.07) one. A look into CC cut-off of $31 \mathrm{~cm}$ needs to be revaluated specially for the studied population. On biochemical parameters MNA had ample support as a 'screening tool' for study population ( $p$ value $=0.00$ ). The sensitivity, predictive value and interobserver concordance coefficients of MNA were all in acceptable limit.

A significant association was observed between nutritional status (under-nutrition) and LOHS.LOHS is considered as an important proxy indicator for surgical complications. Similar results were given by Stratton et al in the U.K. where malnutrition was common in 58\% of patients and was associated with longer hospital stays and poor outcomes. ${ }^{43}$ It highlights the importance of diagnosing and treating malnutrition prior, during and after surgery.

\section{Conclusion}

Nutritional assessment for geriatric population in general and hospitalized ones in particular is of vital significance. If geriatric surgical inpatients are routinely evaluated for their nutritional status and corrective measures initiated in time this can be of immense value to the care seekers and givers. A simple and reliable tool like MNA can be advocated for this purpose which needs less technical expertise and can be administered by nursing and other paramedics.

\section{Strengths and Limitations}

According to the best of our knowledge, this was the first study conducted in Central India which used MNA to identify malnutrition in geriatric patients undergoing surgery and tried to find association between the MNA scores and post-operative clinical outcomes. We used a prevalidated standardized nutritional tool for a specific subgroup of population. The involvement of a single investigator is also an added advantage as it might have reduced observer bias. Limitations of our study was its 
seeming low sample, and interaction with individuals available on the scheduled dates and the study being single centred.

\section{Conflict of Interest: None.}

\section{References}

1. World Health organization. Ageing and nutrition: a growing global challenge. Available fromhttp://www.who.int/nutrition/topics/ageing/en/

2. United Nations, Department of Economic and Social Affairs, Population Division (2017). World Population Prospects: The 2017 Revision, Key Findings and Advance Tables. Working Paper No. ESA/P/WP/248

3. Kulkarni S. Bammidi S.R. Social Security for the Elderly in India Building Knowledge Base on Ageing in India: Increased Awareness, Access and Quality of Elderly Services Thematic Paper 1.Available from-

4. United Nations Population Fund 2017. 'Caring for Our Elders: Early Responses’ - India Ageing Report - 2017. UNFPA, New Delhi, India https://india.unfpa.org/sites/default/files/pubpdf/India\%20Agei ng\%20 Report\%20$\% 202017 \% 20 \% 28$ Final\%20Version\%29.pdf

5. Mathew AC, Das D, Sampath S, Vijayakumar M, Ramakrishnan N, Ravishankar SL. Prevalence and correlates of malnutrition among elderly in an urban area in Coimbatore. Indian J Public Health 2016;60(2):112-7. doi: 10.4103/0019557X.184542. Available fromhttps://www.ncbi.nlm.nih.gov/pubmed/27350704

6. Jacobsen EL, Brovold T, Bergland A. Prevalence of factors associated with malnutrition among acute geriatric patients in Norway: a crosssectional study. BMJ Open 2016;6:e11512. doi:10.1136/bmjopen-2016- 011512

7. Lochs, H. Introductory to the ESPEN Guidelines on Enteral Nutrition: Terminology, Definitions and General Topics Clinical Nutrition, 25;(2):180-6. Available fromhttps://www.clinicalnutritionjournal.com/article/S02615614(06)00051-3/fulltext

8. Donini LM. Eating habits and appetite control in the elderly: the anorexia of aging. Int Psychogeriatr 2003;15(1):73-87.

9. Razak A. J Int Oral Health 2014;6(6):110-16.

10. Thomas B, J. Sandrine. Does home care for dependent elderly improve their mental health? J Health Econ 2016:45;149-60.

11. Carol E. Malnutrition in the Elderly: A multifactorial failure to thrive.

12. Valvona J, Sloan F. Rising rates of surgery among the elderly. Health Affairs 1985;4(3):108-19.

13. Bharathi N. Nutrition Assessment in Elderly Surgical Patients - Need for Screening. J Clin Biomed Sci 2015;5(3):137-8.

14. Nur Fazimah S, Sakinah H, Rosminah Hospitalized Geriatric Malnutrition: A Perspective of Prevalence, Identification and Implications to Patient and Healthcare Cost. https://www.researchgate.net/publication/237077637_Hospitali ze d_Geriatric_Malnutrition_A_Perspective_of_Prevalence_Ident ificatio n_and_Implications_to_Patient_and_Healthcare_Cost

15. Huisman MG, Veronese G, Audisio RA, Ugolini G, Montroni I, de Bock GH, van Leeuwen BL. PREOP study group. Poor nutritional status is associated with other geriatric domain impairments and adverse postoperative outcomes in oncogeriatric surgical patients--A multicentre cohort study. Eur $J$ Surg Oncol 2016;42:1009-1117.

16. Vanderweea K, Claysb E, Bocquaerta E, Gobertc M, Bert Folensd, Tom Defloora Malnutrition and associated factors in elderly hospital patients: a Belgian cross-sectional, multicentre study.
17. Bauer JM, Kaiser MJ, Anthony P, Guigoz Y, Sieber CC. The Mini Nutritional Assessment--its history, today's practice, and future perspectives. Nutr Clin Pract 2008;23:388-96

18. Vellas B. Relationships between nutritional markers and the mininutritional assessment in 155 older persons. - PubMed NCBI [Internet]. Ncbi.nlm.nih.gov. 2018. Available from: https://www.ncbi.nlm.nih.gov/pubmed/11037019

19. Vellas B. The Mini Nutritional Assessment (MNA) and its use in grading the nutritional state of elderly patients. Int J Appl Basic Nutr Sci 1999;15(2):116-22.

20. Y G. The Mini Nutritional Assessment (MNA) review of the literature-What does it tell us? - PubMed - NCBI [Internet]. Ncbi.nlm.nih.gov. Available from: https://www.ncbi.nlm.nih.gov/pubmed/17183419

21. Cohendy R e. Preoperative nutritional evaluation of elderly patients: the Mini Nutritional Assessment as a practical tool. PubMed - NCBI [Internet]. Ncbi.nlm.nih.gov. 2018. Available from: https://www.ncbi.nlm.nih.gov/pubmed/10634918

22. Velasco C. Comparison of four nutritional screening tools to detect nutritional risk in hospitalized patients: a multicentre study. Eur J Clin Nutr 2011;65:269-74. https://www.nature.com/articles/ejen2010243

23. Butterworth C. The skeleton in the hospital closet. Nutr Today 1974;9:4-8

24. Joosten E, Vanderelst B, Pelemans W. The effect of different diagnostic criteria on the prevalence of malnutrition in a hospitalized geriatric population. Aging Clin Exp Res 1999;11:390-4.

25. Chern CJH, Lee S-D. Malnutrition in hospitalized Asian seniors: An issue that calls for action. J Clin Gerontol Geriatr 2015;6(3):73-7.

26. Donini LM, C. Savina, A. Rosano, C. Cannella. Systematic review of nutritional status evaluation and screening tools in the elderly. J Nutr Health Aging 2006.

27. Mathew AC, Jose J. The reliability of Mini Nutritional Assessment (MNA) questionnaire in screening malnutrition among elderly aged 60 years and above. Asian Pac J Health Sci 2015;2(3):47-8.

28. Jose S. and Kumari K.S. Validity assessment of MNA among an elderly population in Kerala, South India. Int $J$ Adv Res 2014;2(2):214-21.

29. Mignini EV, Scarpellini E., Rinninella E. Impact of patients nutritional status on major surgery outcome. Eur Rev Med Pharmacol Sci 2018;22:3524-33.

30. Loan BTH, Nakahara S, Tho BA, Dang TN, Anh LN, Huy ND, Ichikawa M. Nutritional status and postoperative outcomes in patients with gastrointestinal cancer in Vietnam: a retrospective cohort study. Nutr 2018;48:117-21. doi: 10.1016 Available from: https://www.ncbi.nlm.nih.gov/pubmed/29469012

31. Bharathi N. Mini Nutritional Assessment (MNA) of Elderly Hospitalized Patients undergoing Urological Surgery. J Clin Biomed Sci 2016;6(2);49-52.

32. Salive M.E. Serum albumin in older persons: Relationship with age and health status. J Clin Epidemiol 1992;45(3):213-21.

33. Eisenstaedt R. Anemia in the elderly: current understanding and emerging concepts. Blood Rev 2006.

34. Guideline: Assessment and Treatment of Surgical Wounds Healing by Primary and Secondary Intention in Adults \& Children. Br Columbia Provincial Nursing Skin and Wound Committee. June 2011.

35. World Health Organization. WHO guidelines for safe surgery: 2009: safe surgery saves lives. 2009. No. WHO/IER/PSP/2008.08-1E. Geneva: World Health Organization. 
36. Singh M., Stress response and anaesthesia. Altering the peri and postoperative management. Indian J Anaesth 2003;47(6):427-34.

37. Nagar V. A Study to Assess Nutritional Status of Hospitalized Geriatric Age Group Patients of a Tertiary Care Hospital of Central India Using Mini Nutritional Assessment Score.

38. Mahakalkar C. Malnutrition in hospitalized patients; a real concern in surgical outcomes. Int J Res Med Sci 2017;2(1):250-7.

39. Guohao W. Evaluation and prognosis of nutritional status of inpatients with general surgery. Chin J Surg 2005;43(11):6936. DOI: 10.3760 / j.issn.0529-5815.2005.11.003.

40. Nouh F, Omar M, Younis M. Nutritional status of the elderly attending public polyclinics in Benghazi city, Libya. Int $J$ Community Med Public Health 2017;4:39.83-90.

41. Gandhi SJ. Nutritional status of the geriatric population in the field practice area of a medical college in Rajasthan. Int $J$ Community Med Public Health 2018;5(1):220-4.

42. Charlton K. Poor nutritional status of older subacute patients predicts clinical outcomes and mortality at 18 months of follow-up.

43. Stratton RJ, Green CJ, Elia M. Disease related malnutrition: an evidence-based approach to treatment. Clin Nutr 22;6:585.

How to cite this article: Sinha ND, Valecha K, Mishra BN, Sisodiya V, Mohapatra SC. Assessing pre-operative nutritional status in geriatric in patients, and associating it with post-operative clinical outcomes'; in a tertiary care hospital of central India. J Community Health Manag 2019;6(1):1-6. 